up-to-date work of immediate reference, of service to undergraduates and graduates in academic and clinical medicine. The footnotes are a useful guide to the literature, although more references would have been welcomed in the masterly reviews on the sensory, motor and extra-pyramidal systems and in relation to blood supply of nerves, particularly the optic nerve. The section on histology, the introductions to the book as a whole and to the individual sections are in Bacon's category of the "few to be read wholly, and with diligence and attention". These summarize principles, the understanding of which stimulates intelligent observation and deduction, and goes a long way towards counteracting the unhappy tendency to learn anatomy from a book and by rote.

The phenomenon of normal variation is touched on in relation to times of appearance and fusion of primary and secondary centres of ossification. There is no call for detailed descriptions of variants, these are available in the older standard works and in monographs, but in the next edition, more weight, but not necessarily more space, could be given to this interesting topic and to problems of growth. (The chapter on the animal cell has demonstrated the Editors' ability to present a wealth of complicated information briefly and accurately.)

We are greatly indebted to the editors, who have devoted scholarship and practical knowledge to meticulous revision and unification of a lucid, reliable and succinct source of reference, for as Claude Bernard said, anatomy is the basis necessary to all medical investigation, whether theoretical or practical. RUTH BOWDEN

\section{ELECTRONICS DICTIONARIES}

\section{A Dictionary of Electronics}

By S. Handel. (Penguin Reference Books, No. R19). Pp. 384. (Harmondsworth, Middx.: Penguin Books, Ltd., 1962.) $7 s .6 d$.

Six-Language Dictionary of Automation, Electronics and Scientific Instruments

A Comprehensive Dictionary in English, French, German, Italian, Spanish and Russian. Compiled by A. F. Dorian. Pp. 732. (London: Iliffe Books Ltd.; Now Jersey: Prentice-Hall Inc., Englewood Cliffs, 1962). 105s.

7 Wo volumes have recently appeared in the field of electronics literature carrying the title of 'dictionary', but the function, reproduction and price of the two works is very different.

A Dictionary of Electronics is an inexpensive paperbacked issue in the Penguin Reference Books series, which explains about 5,000 electronic terms, each in some two or three lines. A small number of misleading statements can be detected, such as the assertion that all computers (including analogue) operate by logical processes, but in the main the descriptions given are accurate. About 160 diagrams appear by way of illustration, and some faults can be found among these. Thus, the lettering of cathoderay tube electrodes is unconventional (although correct when shown symbolically elsewhere) and a magnetic drum stated to hold 100 words per track has locations numbered from 1 to 99, which may lead to confusion. One diagram appears upside-down, and the mathematical definition of admittance is misleading as a result of an unfortunate choice of brackets. These errors are, however, minor for a book containing so much concise information at low cost.

The second work is a considerably more expensive technical dictionary in six languages; English, French, German, Italian, Spanish and Russian. The volume is divided into two parts, a dictionary section in which translations of some 5,000 terms appear in alphabetic order of the English words, and an index section of alphabetic cross-references for the other five languages.
It has not been possible to verify the accuracy of the whole of this work, but a close investigation of the Russian section has revealed several errors. It must be pointed out, however, that the number of mistakes in relation to the total is small. Some of the less important mistakes would not cruse the sense of a text to be lost, for example, 'alarm bell' has been translated to the equivalent of 'alarming bell', 'power relay' to 'powerful relay', 'magnetizing field' to 'exciting field' and 'magnetostriction' to 'magnetic striction', where more correct words and phrases exist. Other minor errors involve incorrect translation of the words auxiliary, stability, induction, conduction, current, transducer and glow, in various contexts.

More serious errors capable of better translation can best be indicated by their literal English translation as follows: 'basic collector' for 'base-collector', 'characteristics of sinusoid' for 'harmonic response', 'front phase' for 'phase advance', 'continuous constant' for 'long time constant', 'throughout current' for 'loop current', and 'counter coupling' for 'negative feedback'. The most inexplicable translations are 'slope of characteristic' for the word 'mutual' and that for 'phase balance protection' which appears to have no meaning at all.

Other improvements could be made at some points in the matter of Russian style, and a few spelling mistakes (phrases 10545, 10640 and 19060) can be detected. Two phrases (4435 and 4440) appear in ineorrect order in the Russian. Further explanation of the intended meaning of some English words would also be welcome; thus the word 'lay' is from its translations apparently intended to mean the lay of a cable.

To put matters into perspective, however, it must be emphasized that these comments relate to less than 1 per cent of the Russian translations, and the whole work is doubtless one of great value on which the Compiler is to be congratulated.

V. BladyKo

E. M. Defeley

\section{A RADIO TELESCOPE IN YOUR GARDEN}

Radio Astronomy for Amateurs

By Frank W. Hyde. (Amateur Astronomer's Library, Vol. 2). Pp. $236+12$ plates. (London: Lutterworth Press, 1962.) 25s. net.

MATEURS have in the past played a distinguished A part in the development of astronomy, and at the present time their keen and careful work is widely recognized. Indeed many professional astronomers must at times be reassured by the thought that the sky is watched by so many experienced eyes and small telescopes. Similarly, the spectacular results obtained by amateurs in radio communications are a lasting reminder of the immense value of amateur interest in science. With this background, amateur radio astronomers must be welcomed and encouraged.

Mr. Hyde is one of the few serious amateur radio astronomers, and has set up an impressive observatory in Essex. It is thus with great reluctance, that having read this book anxious to welcome it, $I$ must report that it is disappointing. Much of the book is taken up with a strange assortment of astronomical and electronic information which seems to reflect more the personal interests of the author than the needs of a budding radio astronomer. The nowcomer to the subject will probably find the sections on radio astronomy, on aerials and on the adaption of commercial receiving equipment stimulating, interesting but inadequate. The book could be dismissed as a mediocre attempt to fill a place in the Amateur Astronomer's Library were it not for the many serious errors. A. numerically wrong definition of the unit of solid angle, the steradian (in the glossary), an error of about $10^{36}$ in 